\title{
A Comparative Analysis of Gender based Management Styles of Software Project Managers
}

\author{
Ahmed Ali Qureshi \\ Assistant Professor \\ Foundation University \\ Institute of Engineering and \\ Management Sciences, \\ Rawalpindi, Pakistan
}

\author{
Saima Afzal \\ PhD Scholar \\ Allama Iqbal Open University \\ Islamabad, Pakistan \\ Muhammad Asad Saleem \\ PhD Scholar \\ Muhammad Ali Jinnah University \\ Islamabad, Pakistan
}

\author{
Imran Daud \\ Assistant Professor \\ Foundation University \\ Institute of Engineering and \\ Management Sciences, \\ Rawalpindi, Pakistan
}

\begin{abstract}
Management has been studied and has been part of the literature since early twentieth century. With the invention of compute;, related sciences and commercialization of software become part of industry. Softwares were started seeing as projects, and with this software project management evolved.

Different job positions such as software project managers are being advertised. This jobs are equally applied by both males and females members of the society. Some software projects are labeled as highly successful, some successful and others are total loss. There are many possible reasons of failure of a software project ranging from time shortages, costs, changing customer requirements, management techniques, and management styles to many others.

In this research paper the authors have explored the management styles of male and female software project managers. In order to explore the management styles of male and female software project managers(SPM) a questionnaire was developed and was distributed among 120 employees who had served under both male SPMs and female SPMs, in Pakistan. Out of 120 respondents the data was analyzed for 100 respondents (forty males and sixty females). Twenty questionnaires were discarded due to partial completion of the questionnaire, bias towards filing the questionnaires and other such reasons.
\end{abstract}

The data analysis shows that both male and female employees recommend male SPMs. On the basis of the data analysis it is recommended by the authors that male SPMs may be preferred but females SPMs must be given chance having required skills and suitable training and development.

\section{General Terms}

Management styles, software project managers, software project management.

\section{Keywords}

Management styles of software project managers, gender preference of software project managers, Software project management, SPM.

\section{INTRODUCTION}

Management, in general, is organizing resources to achieve the objectives. The objectives can be of a household job or of an organization where one is an employee. Software project management is managing the resources in a best possible manner to complete the software project in a manner that is settled between the client and the project team. In this mortal world, there are no two persons who are not indifferent. The individual differences have always been the discussion in subjects such as psychology. Male and female who are existentially different from each other, so much so that they differ from each other even the way they communicate indifferently throughout the world. However they are minutely indifferent from within their own gender. The job the nature has to take from them is different and so is there a difference in their built, physique, thinking styles and the very nature of approaches to problems. The psychology of them is totally different from each other. Thus whenever, difference between management styles of male or female SPMS are discussed, it fundamentally means that there is a difference in the style of the management, difference towards the problems and their solution and in dealing the staff members. This difference brings many changes in an organization. It changes the overall environment of an organization. The way the projects are conceived, perceived, executed, done, completed and maintained, totally gets different with the change of gender of SPMs. Software project management requires multitude of technical and soft skills for higher success rates.

All organizations which are involved in software developments, from now onwards called as software houses (SHs) in this research paper, are structurally projectized, with variations of weak to strong matrix structures, as well. These SHs can be one doing small projects or large projects, similarly they can be having employee number ranging from 10 to 100 .

The authors have compared the management styles of both male and female SPMs. Questionnaire techniques have been used to find the difference management styles based on gender of SPMs. Relevant statistical techniques have been used to analyze the data and draw on the conclusions. 


\section{DELIMITATIONS}

Keeping in view the limited time and financial resources this study was confined to:

- The Software development organizations of Rawalpindi and Islamabad cities of Pakistan.

- The management style of male and female SPMs.

- The changes brought up by the male SPMs.

- The changes felt by the employees working under SPMs

\section{METHODOLOGY}

As the research was descriptive so to collect the required data; a questionnaire consists of 27 items was distributed among the employees of different software development organizations. The software development organizations were deliberately chosen to be in Islamabad and Rawalpindi cities of Pakistan. Convenient sampling was used to choose the cities and the organizations. The questionnaire was distributed among those male and female employees who served under both the SPMs - Male and female.

The method of selection of sample from the population was purposive cum convenient, as the questionnaire was distributed amongst those male and female employees who served under both the SPMs - Male and female.

\section{LITERATURE REVIEW}

\subsection{Role of SPMs}

The role of SPM is to manage the software project efficiently and effectively, by, for example, assisting employees in their work allocating conceiving, visualizing, programming, documenting, quality assurance, testing, debugging and other duties to employees, ensuring that employees remain on top of the software development routine and latest technologies. Moreover, it is also the part of the job of the SPMs to keep records of employees, meeting overall objectives of the organization, keeping track of the competitors, liaising with clients and industry, keeping the financial record up to date and others.

SPMs occupy pivotal position. The success and failure of the project lies with SPMs. The initiative and skill required for day-to-day administration as well as the dynamism and foresight needed for planning and appraisal of activities come from him/her. Selection of the right type of individual for this important position is, therefore, of vital importance for successful functioning of the organization. The SPM has to be an able organizer, efficient administrator, tactful in handling men and matters and above all, a professionally competent person.

SPM has to take the role of an effective and democratic supervisor. SPMS must be in a position to look for the best in every- thing and exploit all possible means for better functioning of the project/organization. He should keep healthy contact with not only the members of different departments of organization but also with the clients and project members.

A well-knit and systematic scheme of work alone can help in the successful implementation of the plan of a project. There may be different departments and project members claiming a certain amount of expertise in the respective areas. But it has to be emphasized that each one of them forms part of the total organizational effort. It is the overall performance of the organization which determines its success. Close coordination and understanding between different departments and units of the organization is, therefore, of paramount significance to the success of any successful.

\subsection{Definition of Management}

The related literature has been reviewed keeping in view the title of the research. Accordingly, it was found that multiple definitions of management exist with essentially meaning the same. According to Beach (1975, p.5), "Management is the process of utilizing material and human resources to accomplish designated objectives. It involves the organization, direction, coordination and evaluation of people to achieve these goals".

Drucker, considered to be the world's leading thinker on management and organization, defines management as "a specific practice that converts a mob into an effective, purposeful and productive group". (Mescon 1988, p.16)

Terry and Franklin (1982) define management as" a distinct Processes consisting of activities of planning, organizing, actuating and controlling performed to determine and accomplish stated objectives with the use of human beings and other resources". Robbins and Coultan (1991) opined that management is the process of getting activities completed efficiently with and through other people.

Mintzberg (1986) is of the opinion that" management is the process planning, organizing, motivating and controlling in order to formulate and attain organizational objectives".

\subsection{The Process of Management}

The step by step process of effective managemen passes through many phases. It includes planning, organizing, leading and controlling. There are multiple gurus of management who agree to theses four processes of management. Many others provide a greater list. But from a birds eye view, any such greater list can be covered under the four headings, as mentioned above. All type of management at every level goes through the same process but it may be carried out in a different way. The way management is carried in an organization depends on many variables. Structure and type of the organizations, type of people working in it, culture, situational factors and the availability of the resources are among the few variables involved.

\subsection{Levels of Management}

Manager has to perform all of the management functions. Management has become a complete activity. Manager has to add some new products and sell to some new markets. Manager, being an over worked person and due to the increased complexity of job, decides to specialize vertically by assigning the task of supervising subordinates to another person are horizontally by assigning certain tasks.

Managers are traditionally classified within three categories. Parsons, a sociologist, describe these levels in terms of functions, they fulfill for organization. According to Parsons (1980), people on the technical level are primary concerned with day-to-day operations and activities required for efficiently smoothly flowing production or services. Those on the management level are primarily concerned with 
internal administration and coordination of diverse organizational activities and subunits. Managers on the institutional level concern themselves primarily with making long - range plans formulating objectives, adopting the organization to change, and monitoring the relationship between the organization and the community and society in which it operates. A more common way of describing the levels of management is to call them supervisory or operating management, middle management and top management.

\subsection{Management Skills}

According to Oxford dictionary (1994), skill is ability to do something well. So a skill is an capability or talent in doing a job / task. Therefore, ability of doing management well is management skill.

Donnelly and Gibson (1986) have devised various management skills i.e.

\subsubsection{Technical Skills}

Ability of using precise information, facts, knowledge is known as Technical management skill, for instance, techniques and resources in performing work. Accountants and their supervisors, engineers and their directors or doctors and nursing supervisors must have the technical skills to perform their management jobs [6].

\subsubsection{Human Relations Skills}

Manager has to complete the work / job / project with help of and through other people hence, their interpersonal skills are very important. The interpersonal skill is vital and necessary at all managerial levels / ladders. Indeed, it is a mirror image of a manger's abilities of leadership. [6].

\subsubsection{Communication Skills}

Effective communication is the written and oral transmission of common understanding is vital for effective management performance[6]s. It is a skill that is critical to success in every field but it is crucial to mangers who must achieve results through the effort of others [6].

\subsubsection{Conceptual Skills}

This is the ability to comprehend the larger picture, all the working behind the scenes, the difficulty and complication of the overall project / institutions, and how the jigsaw fit in. A manager must know how interrelated cog wheels of the organization work and contributes together and synergize with each other.

\subsubsection{Decision Making Skills}

All management has to make and take decisions or have to choose from among multiple options and substitutes and the worth and value of these choices and decisions defines their level and scale of success and effectiveness. A manager's decision-making skills in choosing an action plan and taking heed from influenced from the analytical skill.

\subsubsection{Analytical Skills}

The use of scientific / technical way / techniques to explain and solve problems is called analytical skills. Thus, it is a skill to identify and seek key pivotal aspects, how they might interconnect and relate, and the functions they play in case of any problem / situation. It is actually a skill to identify and assess. It is required to know and comprehend the problem at hand and to deploy and develop a plan of action [6].

\subsection{Management Styles}

Every individual is unique and so does the mangers. Some are expert in an area and some are jack of all. Some are perfectionist and others are not. Some are absolute rulers, some people oriented in their decisions while still there are some who believe in total freedom. Some have orientation towards delegation of authority and others are not. Some want to be in the good books of every one and remain popular while others may work total differently. But history has proved that there are no unique properties / characteristics that a manager must hold to be successful however, there are set of abilities from where a manager must have many abilities to be a successful manager.

There is a broad pattern of actions an individual leader demonstrates in seeking to motive and direct his or her employees. Once managerial style is heavily influenced by once individual competencies and, in torn, substantially impacts the climate that effect employee's motivation (Tracey, B.W. and Franklin, H. 1998 p.96).

To choose the best management styles require conclusion on current situations and conditions and seeking the optimal way to persuade people so that they may struggle and do their best keenly and passionately in order to achieve the overall targets and goals. A good example can be an orchestra leader who gets co-ordinate sounds produced and correct tempo through the integrated effort of musicians. The music produced has not only to be a co-ordinate effort but also to suit the situation it is being played. The orchestra responds to the quality of the director.

Management styles can be viewed in term of autocratic and democratic behavior. Autocratic style is authoritative and directive. It has centralized authority and unilateral decisions with no participation. Autocratic managers rely on legitimate reward, and coercive power to motivate others. Democratic managers consult with subordinates in decision- making, encourage participation and delegate authority. They use referent and expert power to influence others. If we free reign styles to autocratic and democratic styles, then these can be graphically presented as follows: 


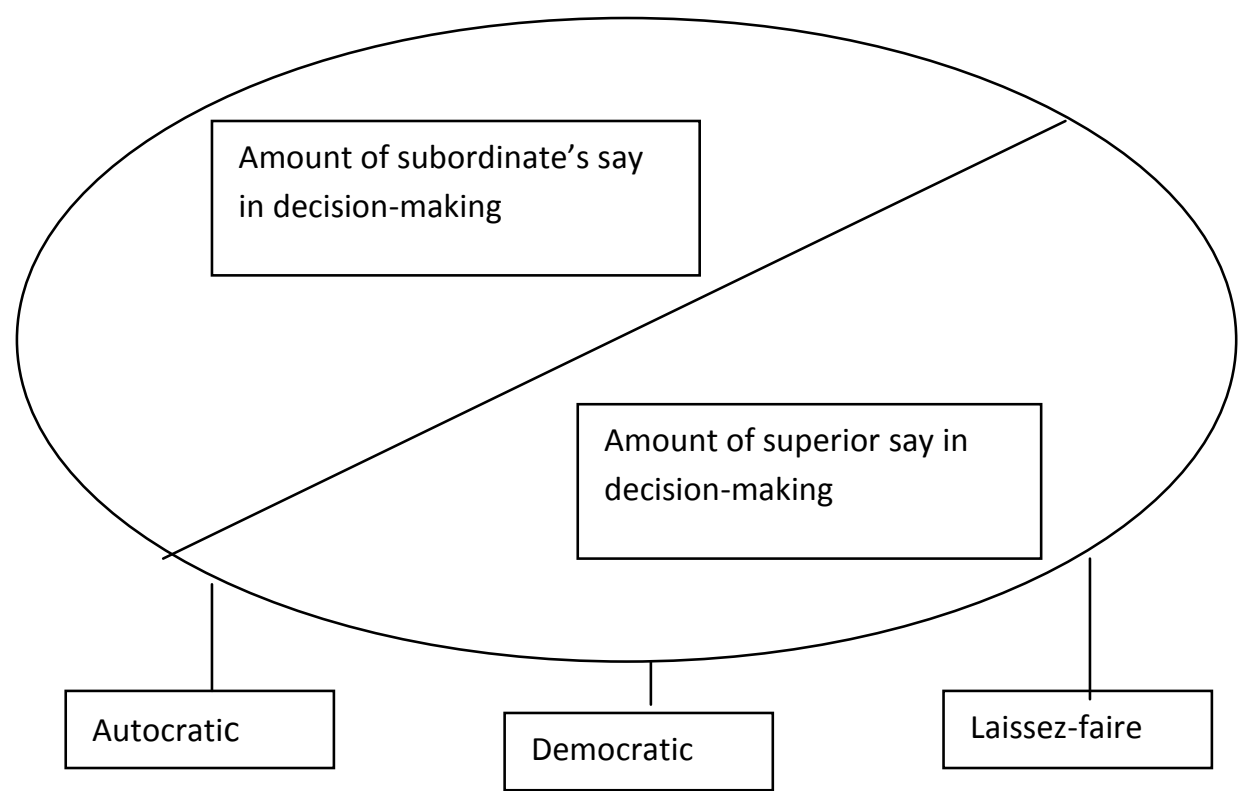

Fig 0: Management Styles and Behaviors

Source: Henery, L.T. \& Stephen, J.C. (1982) Management, New York: John Wiley and Sons.

\section{METHOD AND PROCEDURE OF STUDY}

\subsection{Population}

Following were the population of the study

1. All SHs of Pakistan.

2. All employees who have worked under SPMs.

\subsection{Sample}

Following were taken as the sample of the study

1. All SHs of Rawalpindi and Islamabad.

2. Employees who have worked under both male and female SPMs.

\subsection{Instrumentation}

The questionnaire is adopted and modified with permission from the research work of Saima, 2010. The questionnaire was used for collection of data. Questionnaire was distributed to both male and female employees of the SHs who have worked under both male and female SPMs.

\subsection{Pilot Testing}

For pilot testing, the questionnaire was administered on from the members of the sample not included in the sample.

\section{ANAL YISIS OF DATA}

The questionnaire was distributed among 127 employees who have worked under both male and female SPMs. Out of 127 questionnaires only 100 were selected for data analysis. 27 questionnaires were discarded due to either non legibility or missing values or due to non random fillings. Finally questionnaires from 60 females and 40 males were used for analysis. Percentage analysis of each question is done using tabular percentages and histograms. Interpretation of the same is also given along.
Do you think that an overall administration has changed positively under the Male SPMs [6]?

$42.5 \%$ of males and $50 \%$ of females felt that an overall administration changed positively under the male SPMs, and $42 \%$ of females felt that to some extent the change is positive. $7.5 \%$ of males and $7 \%$ of females did not feel that the change is positive.

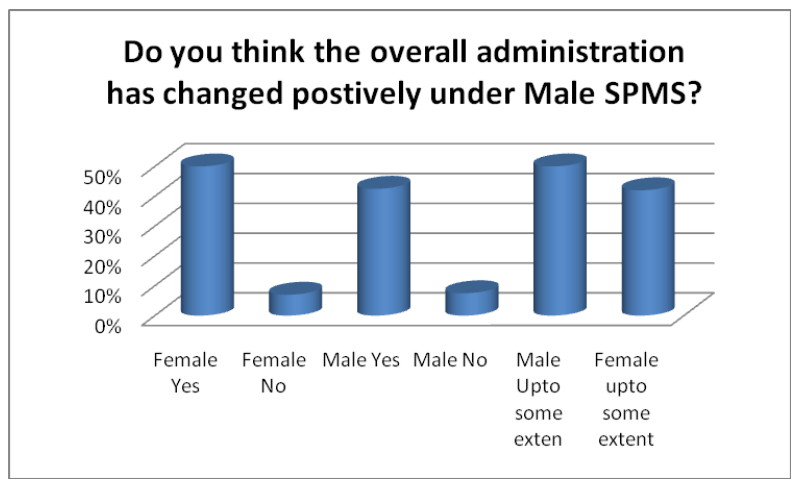

Figure 1: Percentage responses

Do you think that male SPMs distribute work load equally [6]?

The data collected revealed that $70 \%$ of males and 60 of females agreed that the male SPMs distribute the work load equally. The same is shown below in the form of histogram. 


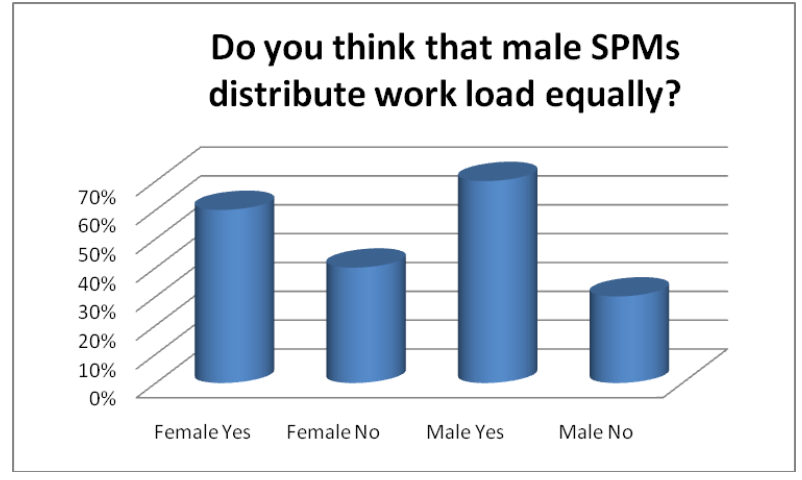

Figure 2: Percentage responses

Which SPM is easy to communicate with [6]?

$70 \%$ of the male employees felt easy to communicate with the male SPMs and $38 \%$ of the female employees felt easy to communicate with male SPMs..

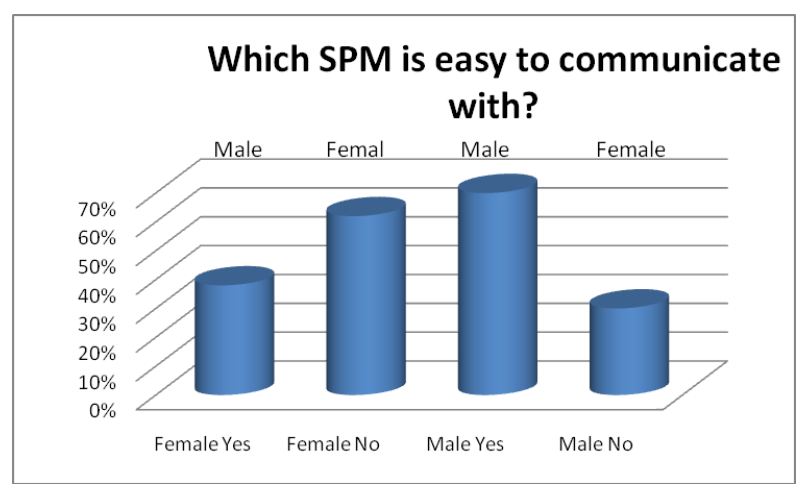

Figure 3: Percentage responses

Which SPMSs are more biased [6]?

$62.5 \%$ male and $62 \%$ female agreed that female SPMs are more biased. The same is shown below in the form of histogram.

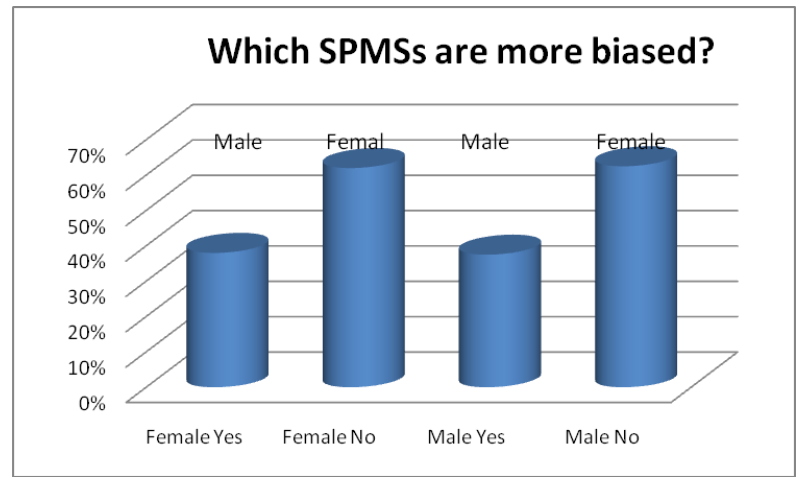

Figure 4: Percentage responses

Which SPM is overall more effective for smooth running of a project [6]?

$82.5 \%$ of male employees and $50 \%$ of female employees were in favor of male SPMs. The same is shown below in the form of histogram.

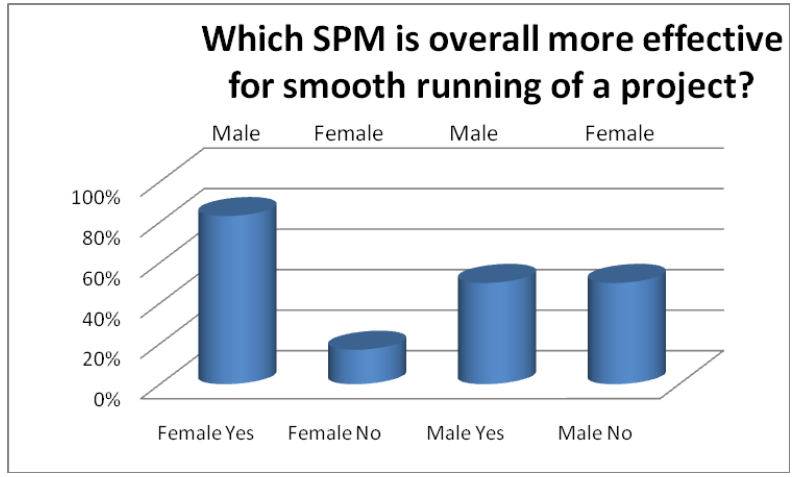

Figure 5: Percentage responses

Which SPMs are directly approached by the employees, "Male or female" [6]?

According to collected data $80 \%$ males and $87 \%$ females agreed that male SPMS are directly approached by the employees and client. The same is shown below in the form of histogram.

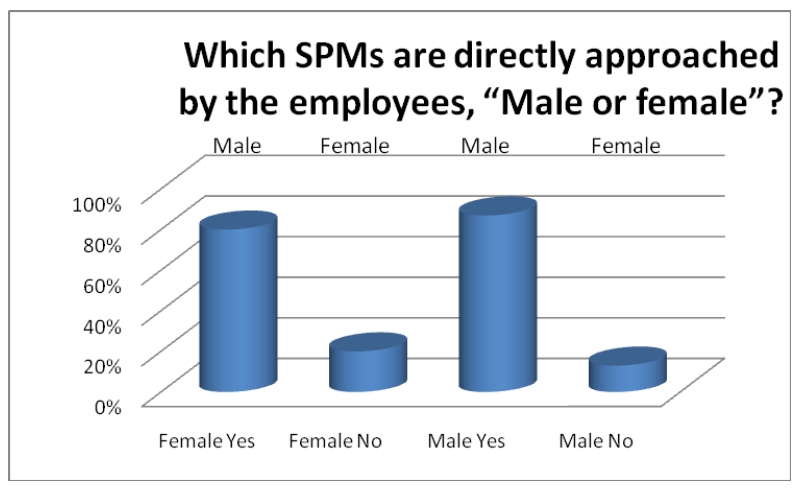

Figure 6: Percentage responses

With which SPM the written communication increases, "Male or Female" [6]?

Collected data revealed that $80 \%$ male and $83.33 \%$ females felt that that written communication increases with the male SPMS than female SPMs. The same is shown below in the form of histogram.

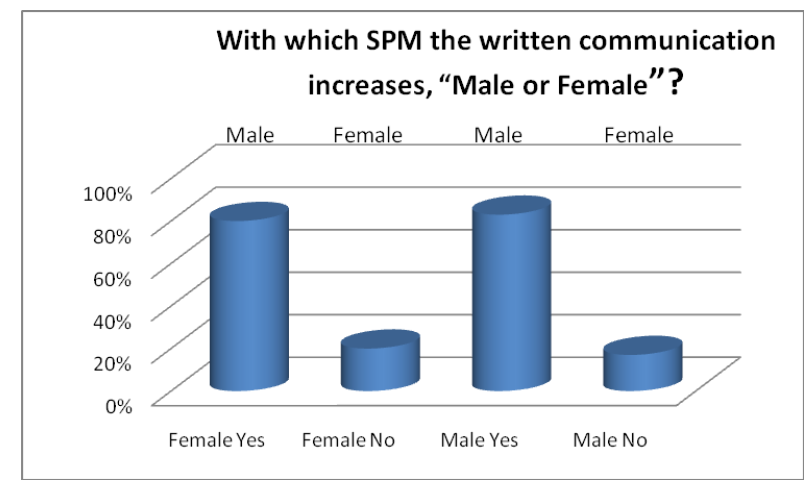

Figure 7: Percentage responses

Under which SPM the employees are more independent for decision- Male or Female [6]?

$52.5 \%$ of males and $55 \%$ of female employees agreed that they were more independent for taking decision regarding different tasks while working under the male SPMs. 


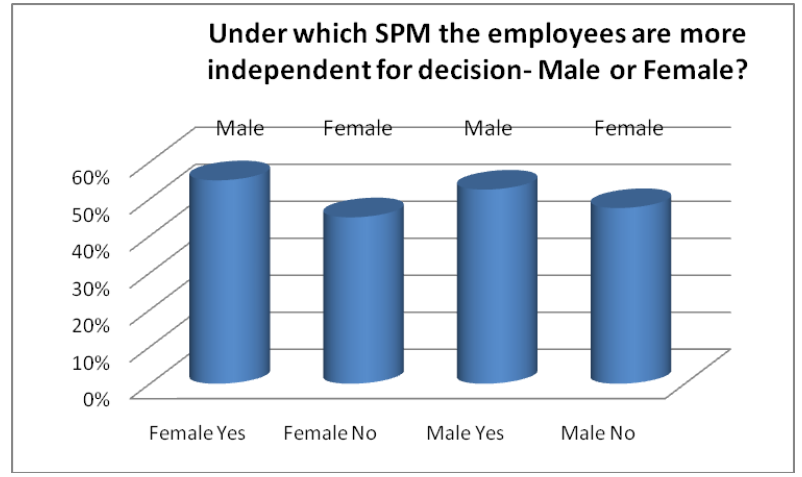

Figure 8: Percentage responses

The performance of employees showed Improvement under which SPM- Male or Female [6]

$75 \%$ of male and $53 \%$ of female employees revealed that the employee performance showed improvement under the male SPMs. The same is shown below in the form of histogram.

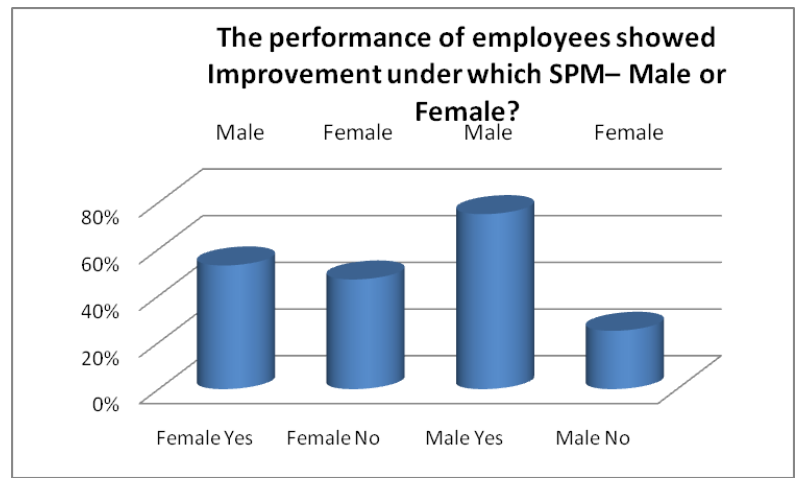

Figure 9: Percentage responses

Under which SPMs the project meetings / work break

down and results are more organized - Male or Female?

According to $77.5 \%$ male and $55 \%$ female employees observed that the project meetings / work break down and results were more organized under the leadership of male SPMs. The same is shown below in the form of histogram.

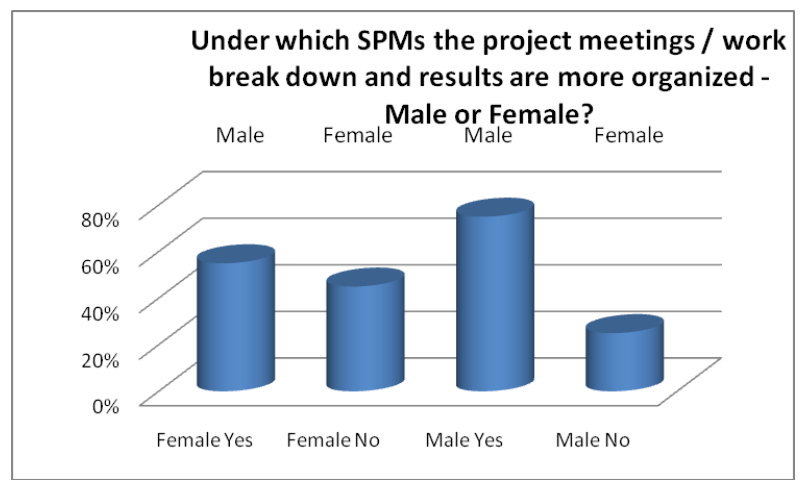

Figure 10: Percentage responses

An overall project / organization atmosphere improved under which SPM Male or Female [6]?
The data collected showed that $65 \%$ of male and $57 \%$ of female employees were satisfied with the male SPMs for the improvement of an overall atmosphere. The same is shown below in the form of histogram.

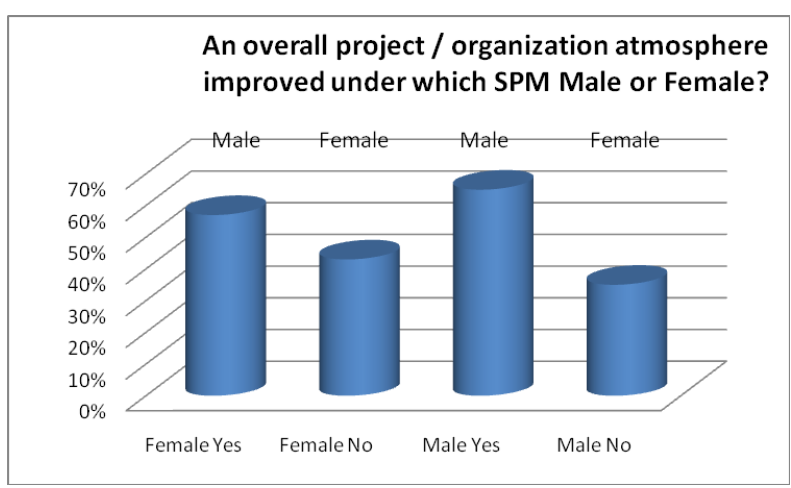

Figure 11: Percentage responses

Which SPM organizes the project / team meetings in better way [6]?

$65 \%$ male and $57 \%$ female employees expressed their opinion in favour of male SPMs that they were affective in organizing the project / team meetings in better way. The same is shown below in the form of histogram.

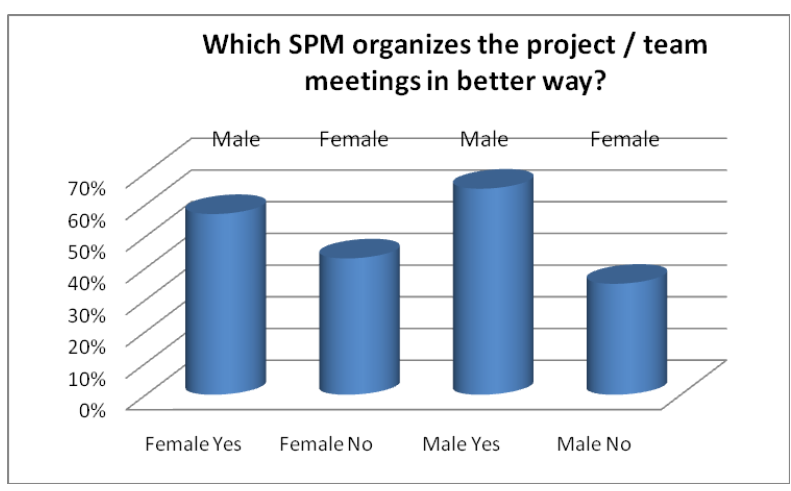

Figure 12: Percentage responses

Which SPMs are more democratic - Male or Female [6]?

The data showed a slight difference in response to democratic approach for administration between male and female SPMs. $10 \%$ of the females did not give any response. $60 \%$ of the female employees felt that male SPMs were more democratic, whereas $52.5 \%$ of male employees felt that female SPMs were more democratic. The same is shown below in the form of histogram.

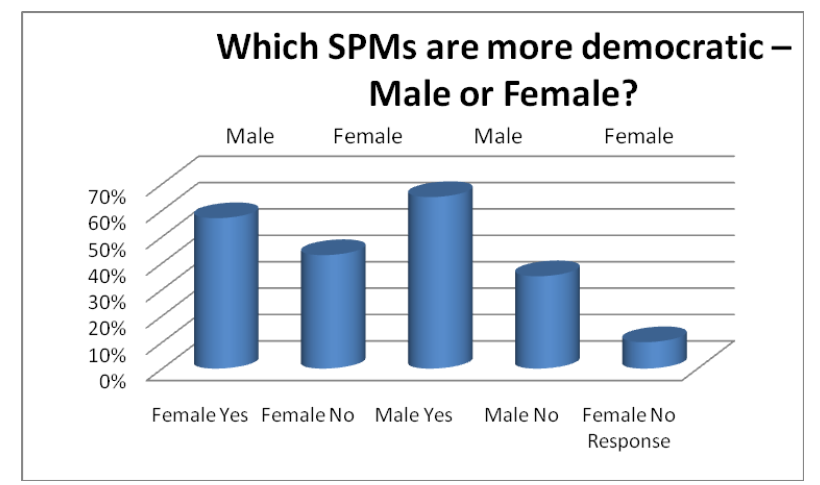

Figure 13: Percentage responses 
Do you think that female SPMs show their authority more in comparison to male SPMs [6]?

$73 \%$ of females responded that female SPMs showed their authority more in comparison to the male SPMs. Whereas 70\% male employees said that female SPMs did not show their authority. The same is shown below in the form of histogram.

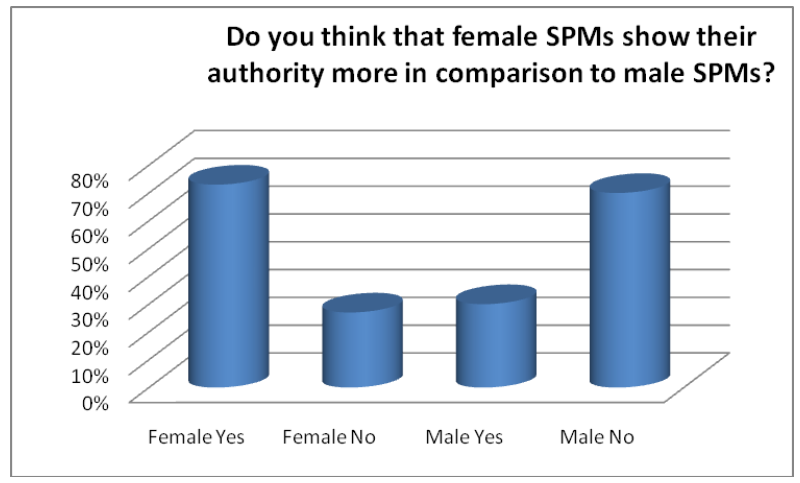

Figure 14: Percentage responses

Do you think that male SPMs use the authority more in comparison to female SPMs [6]?

$75 \%$ of male and $67 \%$ of female employees said that male SPMs use their authority more in comparison to female SPMs. The same is shown below in the form of histogram

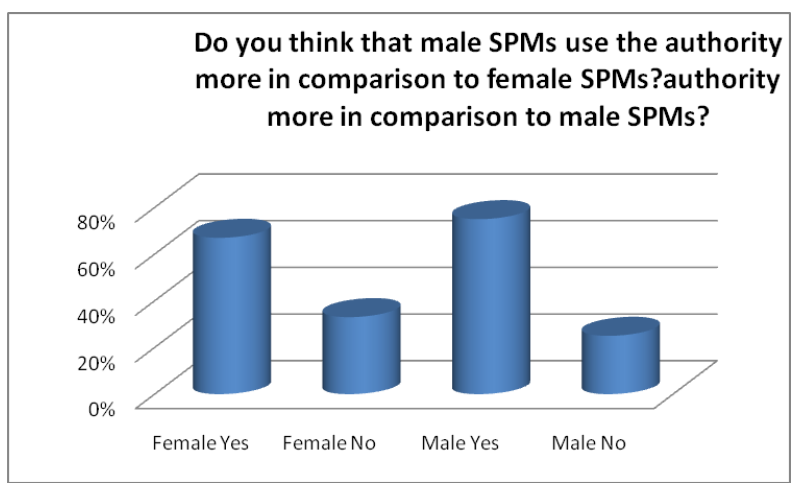

Figure 15: Percentage responses

Do you think that male SPMs are quick in decision making [6]?

$82.5 \%$ of male and $85 \%$ of female employees felt that male SPMs were quicker in decision making. The same is shown below in the form of histogram.

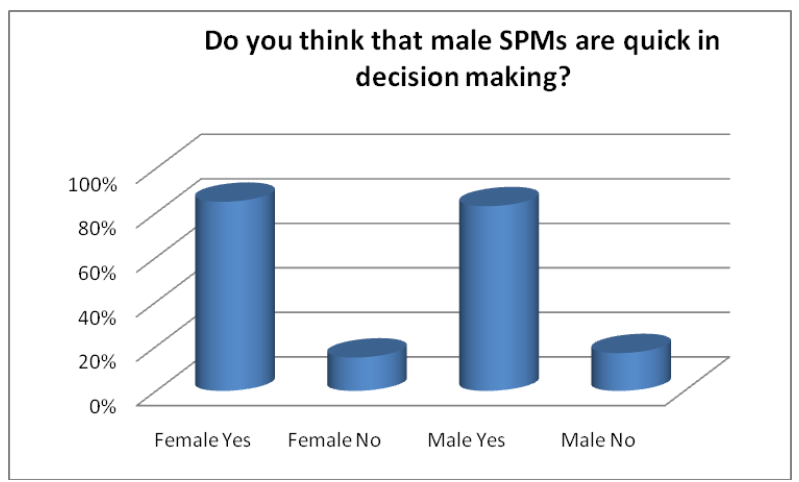

Figure16: Percentage responses
Do you think that male SPMs are bolder in taking initiative [6]?

$87.5 \%$ of male and $90 \%$ of female employees felt that male SPMs were bolder in taking the initiative. The same is shown below in the form of histogram.

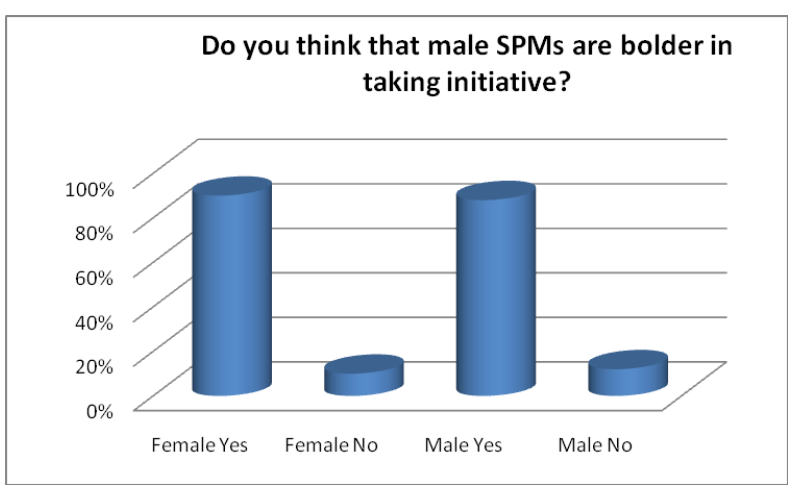

Figure 17: Percentage responses

Do you think male SPMs have more leadership qualities[6]?

$80 \%$ of male and $72 \%$ of female employees revealed that male SPMs had more leadership qualities in them. The same is shown below in the form of histogram.

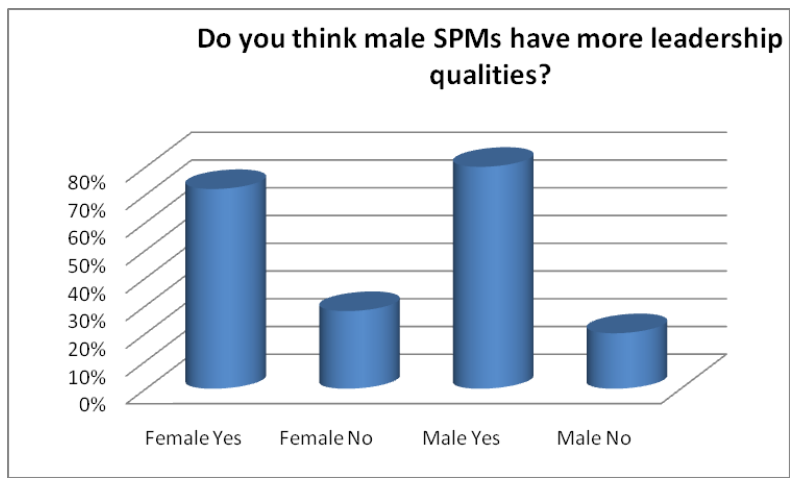

Figure 18: Percentage responses

Do you think that male SPMs are more problem solving in their approach [6]?

$77.5 \%$ of male and $70 \%$ of female employees came up with the opinion that male SPMs were more problem solving in their approach. The same is shown below in the form of histogram.

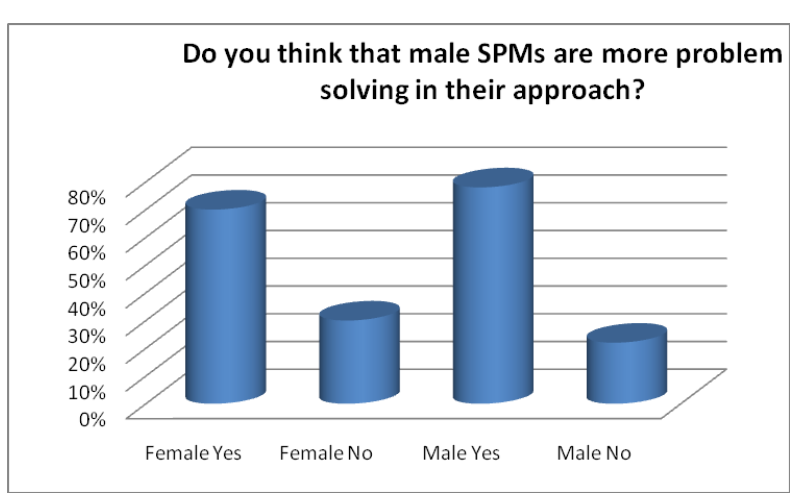

Figure 19: Percentage responses 


\section{SUMMARY}

Data was gathered after sighting the literature, conducting the interview, and collecting the data came to the conclusion that project management is considered a job of males. Keeping in view the traits of the administration and management; such as leadership qualities, decision making and communication skills, taking initiative, problem solving approach and democratic style, the males SPMs were found more skilled and approachable in comparison to the female SPMs in the $\mathrm{SHs}$ of Rawalpindi and Islamabad. The literature sighted proves that it is not the gender that matters but the qualities in any gender, which matters a lot. This is also a fact the more and more females are turning towards the management of the project and are doing their jobs successfully. Males and females both the SPMs failed at times; but not due to the fact that were males or females but due to fact that they lacked the qualities that are required in any project manager. In the end the sighted literature also proved that gender differences do not matter. The Europe Is not in favour of the gender discrimination but the same proved when the collected data was analyzed. Though the males lead in the leadership and in managerial qualities as the data proves but the difference is not high enough to reject or to ignore the female gender totally as to be the SPM.

\section{ANALYSIS}

The researcher did not only collect data by designing the questionnaire but also interviewed the employees and the SPMs individually.

The data collected by random sampling from 40 male and 60 female employees were analyzed on simple percentage. The overall collected data revealed that the employees of SHs are over-burdened due to the role related jobs other than the project only.

The management style of male and female SPMs, the collected data revealed that the male SPMs are good leaders and project managers. They were considerate, easy to approach good managers, leaders, record keepers, communicators and brought an overall improvement in the software development process at any given SH. They were evaluated as more democratic in their management style. Female SPMs, as per the collected data proved their management style as autocratic as they were not approachable directly by the employees and client, they were more biased in their decisions. They could not be approached and so they were unable to understand the problems of the organization and therefore faced many administrative problems.

Female SPMs were disturbed because the male employees were not under their appropriate control, the employees and staff was creating problems due to the loose management and administration. They were also feeling uncomfortable for correspondence with the client, upper management and government bodies. They remained unsuccessful in establishing a good relation with the community as well. They did not show any compatibility with the community politics and influential people this was bringing-in many administrative problems to the project.

\section{CONCLUSION}

On the whole both the male and female employees felt comfortable with male SPMs but they stressed on the qualities of the SPMs and do not consider gender as important factor for the appointment as project manager. In the light of the present scenario, both the female and the male employees recommended male SPMs. Though in a straight question regarding the choice of the gender of SPM the difference is very slightly went in favor of the male principal but the qualities which makes a project manager a successful leader overwhelmingly went in favor of male SPMs. The literature sighted recommends that traits of the SPMs are dominating factor and the gender has nothing to do with it. Now a days more and more females are turning toward software industry and they are showing success as well.

\section{RECOMMENDATIONS}

In the light of collected data, Male employees and female employees, the researchers recommend the following for an overall improvement in the SHs.

1. Male employees with the experience in the field may be appointed as SPMs.

2. Employees' non-project burden may be reduced.

3. Project management training may be made a regular feature for the employees of SHs.

4. Appointment of SPMS may be made after the conduct of written test and interview. The test should be standardized and designed by professionals of repute in the field of project management and relevant degrees.

5. Proper training of the SPMs and employees with the experienced persons in the field of project management may be planned.

6. Females only with proper administrative and managerial training may be appointed as SPMs.

\section{REFERENCES}

[1] Beach, D.S. (1975) Personnel: The Management of People at Work, New York: Macmillan Publishing Company Inc.

[2] Drucker, P. (1954) The Practice of Management, New York: Harper and Brothers.

[3] Mintzberg, H. (1980) The Nature of Managerial Work, New Jersey: Englewood Cliffs Prentice Hall Inc.

[4] Pocket Oxford Dictionary, 1994, Oxford University Press, Walton Street Oxford OX2 6DP

[5] Robbin, S.P. \& Coultor, (1991) Management, New Jersey: Englewood Cliffs, Prentice Hall.

[6] Saima Afzal, (2009), Comparative study of males and females principals of Fauji Foundation Schools. (Dissertation Research, Allama Iqbal Open University).

[7] Terry, G.R. \& Franklin, S.G. (1982) Principles of Management, U.S.A: Richard D. Irwin Inc.

[8] Tracy, B. W. \& Franklah, H. (1995) Re-engineering Performance Management, Florida: St LUCIE press. 